\title{
Self-management of patients with heart valve replacement and its clinical outcomes: a systematic review
}

\author{
Shirdel Zandi ${ }^{1}$, Behzad Imani ${ }^{2}$, Gholamreza Safarpor ${ }^{3}$, Salman Khazaei ${ }^{4}$ \\ ${ }^{1}$ Department of Operating Room, Student Research Committee, Hamadan University of Medical Sciences, Hamadan, Iran \\ 2Department of Operating Room, Faculty of Paramedicine, Hamadan University of Medical Sciences, Hamadan, Iran \\ ${ }^{3}$ Department of Heart Surgery, School of Medicine, Hamadan University of Medical Sciences, Hamadan, Iran \\ ${ }^{4} \mathrm{PhD}$ of Epidemiology, Research Center for Health Sciences Hamadan University of Medical Sciences, Hamadan, Iran
}

Kardiochir Torakochir Pol 2021; 18 (1): 40-49

\begin{abstract}
Introduction: For patients with heart valve replacement, self-management can play an essential role in the management of their condition.

Aim: This review aimed to identify the aspects of self-management and its clinical outcomes in patients with heart valve replacement.

Material and methods: In this systematic review, the peer-reviewed research literature on self-management of patients with heart valve replacement was assessed. Since May 2020, the PubMed, Scopus, and web of science databases were searched regardless of time and language limitations. The eligibility of the articles was assessed by title or abstract according to the search strategy. Article selection was applied regarding to inclusion and exclusion criteria. Also, article screening was conducted by 2 independent authors.

Results: Twenty-five studies were considered in this systematic review. For inclusion, the self-management of patients had to have prerequisites, appropriate training, and be applicable in the aspects of anticoagulation therapy self-management, international normalized ratio (INR) self-testing, low-dose INR self-management, and heart valve function self-monitoring. In this method, through proper management of INR levels and anticoagulation therapy, the complications rate could be reduced and the patients would be able to diagnose functional disorders in the early stages by monitoring the valve function. This procedure was able to prevent the progression of complications.

Conclusions: Self-management is an applicable protocol in the field of anticoagulation therapy, INR control, low-dose INR management, and the monitoring of cardiac valve function. This protocol could improve the quality of treatment for these patients through upgrading the care standards.
\end{abstract}

Key words: self-management, heart valve replacement, heart valve prosthesis implantation.

\section{Introduction}

Valvular heart disease is one of the most common cardiovascular diseases, affecting over 100 million patients worldwide [1]. This number is rising due to the ageing population, which leads to growing public health problems [2]. Prosthetic heart valve (mechanical or bioprosthetic) replacement is an effective intervention for severe valvular heart disease. Approximately 30 million heart valves are implanted every year globally [1]. As heart valve surgery has markedly improved the survival and health-related quality of life in the last decades [3], the rate of this type of surgery has increased [4]. Also, mechanical prostheses exhibit higher stability but require anticoagulation with vitamin $\mathrm{K}$ antago- nists. Anticoagulation remains a critical issue for patients with valvular prostheses, with an annual risk of bleeding of $1-2 \%$. Anticoagulation administration is responsible for $60-$ $75 \%$ of mechanical valve-related mortality $[5,6]$. The aim of the application of bioprosthetic valves is to avoid the inconvenience and risks associated with long-term anticoagulation administration [7-9]. Among the patients undergoing aortic valve replacement, long-term mortality rates were similar to those who received bioprosthetic grafts. However, mechanical valves and bioprostheses were associated with a higher long-term risk of reoperation and endocarditis with a lower risk of stroke and haemorrhage [9]. Nonetheless, the return to daily life after surgery is faced with physical, men-

Address for correspondence: Behzad Imani PhD, Assistant Professor, Department of Operating Room, Faculty of Paramedicine, Hamadan University of Medical Sciences, Hamadan, Iran, e-mail: behzadiman@yahoo.com

Received: 25.12.2021, accepted: 15.02.2021. 
tal, and social challenges [10]. After the surgical procedure of mechanical valve replacement, the patient must adhere to lifelong anticoagulation therapy. In this case, the limited therapeutic index of warfarin requires regular assessment of international normalized ratio (INR) to adjust its anti-coagulation intensity, improve the quality of anticoagulation management, and prevent complications with either higher or lower blood-coagulation levels [11]. Frequent long-term monitoring of INR values can lead to proper management, which has physical, psychological, social, and financial consequences for both patients and the health care system [12]. In developed western countries, patients in need of oral administration of warfarin anticoagulation have initiated the application of portable coagulometers for self-testing and self-management $[13,14]$. The literature indicates that self-monitoring might increase the patient's monitoring frequency and reduce the incidence of complications $[15,16]$.

\section{Aim}

The purpose of this review was to identify the aspects of self-management and its clinical consequences in patients with heart valve replacement.

\section{Material and methods}

In this systematic review, the PRISMA statement was used to clarify the present report [17]. The question addressed in this review was: What are the aspects of selfmanagement and its clinical outcomes in patients with heart valve replacement? In this systematic review, the databases of PubMed, Scopus, and Web of Science were searched since May 2020, with no limitations of time and language. The authors also reviewed the references of eligible studies. The search was applied as follows: (self-care OR self-management) AND (heart valve replacement OR Heart valve surgery OR Heart valve prosthesis implantation $O R$ Heart valve prosthesis OR Mechanical heart valve replacement OR prosthetic heart valve replacement).

Titles and abstracts of all identified articles were screened by $\mathrm{BI}$ and $\mathrm{SZ}$ to exclude any irrelevant papers. The full text of the remaining articles was reviewed to find the relevant studies based on the inclusion criteria. Any repeated studies, reviews, case reports, or letters to editors were excluded.

The following information was extracted independently by 2 authors: the name of first author, year of publication, country of research, study design, duration of follow-up, type of valve, main finding, and practical points.

\section{Ethical approval}

This study is the result of a student thesis that has been registered in Hamadan University of Medical Sciences of Iran with the ethical code IR.UMSHA.REC.1399.332.

\section{Results}

The literature search and selection process are depicted in Figure 1. In total, 385 relevant records and their references were searched from 3 different databases. Based on the endnote application, duplicated papers were removed. Three hundred and fifty-one articles were screened based on title and abstract. During the screening process, 307 records removed by checking title and abstract, and in 44 records the full text was reviewed completely. As shown in Table I, following full-text evaluation, 19 full texts were removed, and 25 full text articles met the eligibility criteria for the systematic review [18-41] (Figure 1).

These studies were conducted between 1998 and 2016. Four studies were conducted in Denmark [18, 22, 26, 39]; 14 in Germany [21, 23, 28-34, 36, 37, 40-42]; 2 in the United States [20, 25]; 1 in China [35]; 1 in France [27]; 1 in the Netherlands [38]; 1 in Northern Ireland [19], and 1 in South Korea [24] (Table II).

Study designs included those based on randomized controlled trials (RCT) $(n=17)$. Other designs included quasi-experiment studies $(n=6)$, a matched cohort study $(n=1)$, and a retrospective study $(n=1)$. The lowest sample size in these studies was 30 (40), and the highest was 1818 $(29,32,33)$ (Table II). In most studies, the patients studied had mechanical valves $(n=24)$, and in 1 study the type of valve was not known (Table II).

These studies were aspects of anticoagulation therapy self-management $(n=9)$, INR self-testing $(n=9)$, low-dose INR self-management $(n=4)$, and heart valve function selfmonitoring $(n=3)$ (Table I).

\section{Discussion}

\section{Prerequisites and principles of training for the initiation of self-management in heart valve patients}

Self-management in patients with heart valve replacement requires a series of prerequisites and training. Despite these conditions, self-management is considered as a learnable behaviour. Based on the opinion of Sidhu et al., it is a reliable method that can be easily learned for anticoagulation management [19]. One of the most important prerequisites for self-management is the financial support of these patients [27]. Azarnoush et al. showed that the main factors prohibiting INR self-measurement are its high cost and difficulty in obtaining strips [27]. Accordingly, one of the most important prerequisites for the selfmanagement of these patients is access to self-monitoring devices and all disposables necessities [27, 38]. Another study found that these patients should have family support based on the patients' needs [22]. In addition, following the start of self-management, these patients should contact the medical centres to report the results of tests, medications, and complications [22, 32].

In these patients, training is a factor affecting the quality of the self-management [41], and these patients need to receive the necessary training before initiation of selfmanagement $[22,30]$. Some studies have proposed the start time of self-management training at 6-11 days post surgery $[31,32,36]$. At the end of the training courses, the patients should be evaluated for self-management compe- 


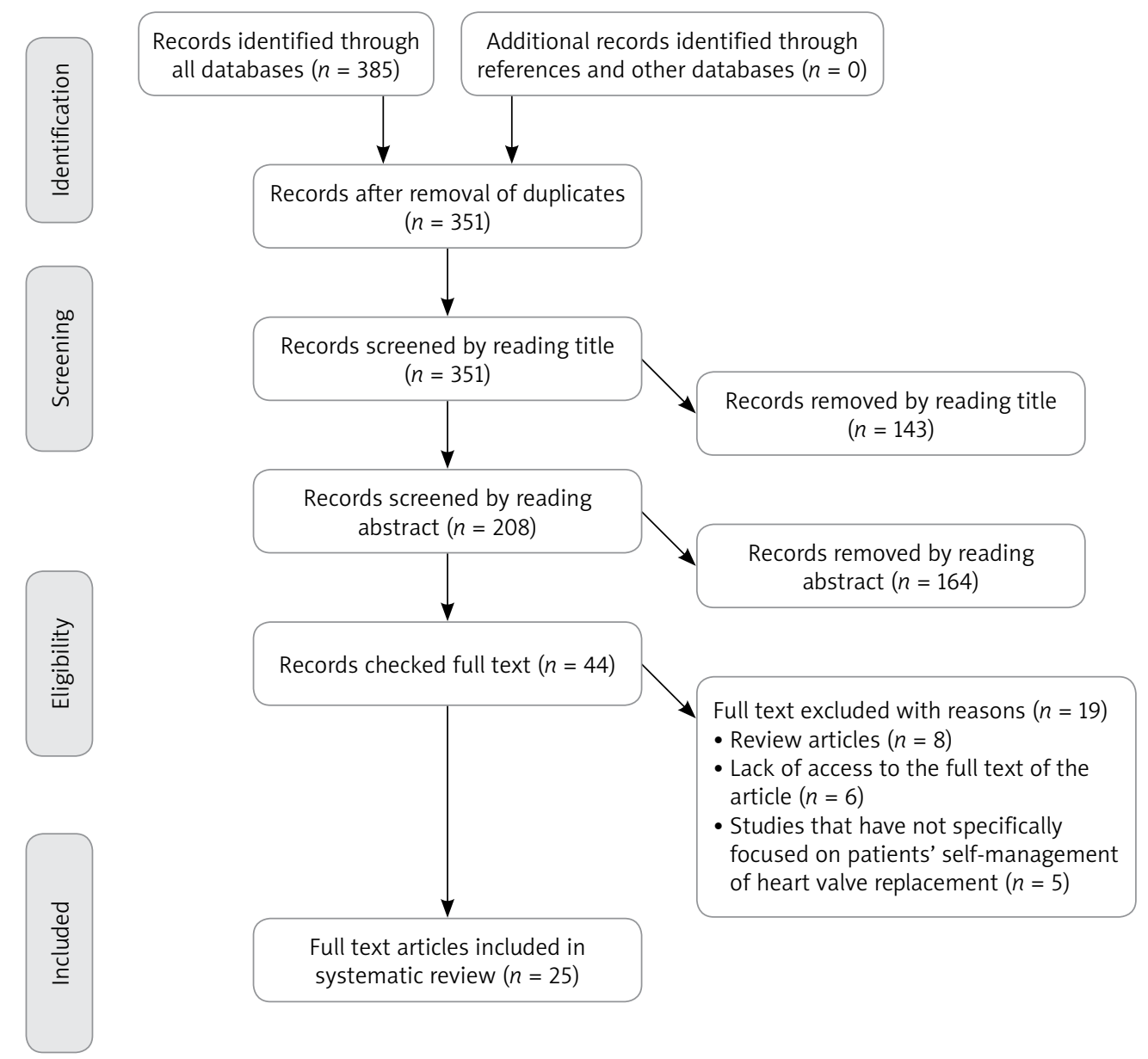

Figure 1. Flow diagram of the study selection for the review process

Table I. Aspects of self-management in heart valve patients

\begin{tabular}{ll}
$\begin{array}{l}\text { Anticoagulation therapy } \\
\text { self-management }\end{array}$ & $\begin{array}{l}\text { Christensen TD (2003), Christensen TD (2001), Christensen TD (2016), Sidhu P (2001), Thompson JL } \\
\text { (2013), Hasenkam JM (1998), Soliman Hamad MA (2009), Koertke H (2007), Mair H (2012) }\end{array}$ \\
\hline INR self-testing & $\begin{array}{l}\text { Azarnoush K (2014), Thompson JL (2008), Jeon HR (2015), Körtke H (2001), Eitz T (2008), Kortke H } \\
\text { (2001), Koertke H (2003), Chen QL (2015), Koertke H (2000). }\end{array}$ \\
\hline Low-dose INR self-management & Koertke H (2015), Koertke H (2005), Koertke H (2007), Koertke H (2010) \\
\hline Heart valve function self-monitoring & Fritzsche D (2007), Fritzsche D (2007), Fritzsche D (2004) \\
\hline
\end{tabular}

tence $[19,38]$. This process should then be started gradually and continued under supervision [22]. In self-management training, theoretical and practical skills should be considered. Patients should be taught how to use coagulometer devices, pt-test strips, etc. [26, 28]. Self-management requires a blood sampling technique that uses a punctured finger, which must be learned in a precise method, as well as principles hygiene $[20,25]$. These patients should also be trained regarding, for example, vitamin $\mathrm{K}$ antagonists, diet, drug interactions, methods of INR control outside the target range, precautions in anticoagulant administration, complications of medications, surgical wound management, alcohol consumption, use of narcotics, daily life, exercise and physical activity, stress management, and ways of communicating with the hospital $[21,24,27]$.

\section{Anticoagulation therapy in self-management}

Most studies of self-management in heart valve replacement patients have been conducted in the field of INR self-management and anti-coagulation therapy. The results of these studies showed that self-management of oral anticoagulant therapy provides an accurate treatment quality for mechanical heart valve patients [22]. Self-management of oral anticoagulant therapy is a feasible and safe concept for selected patients with mechanical heart valve prostheses, in whom this method provides better quality of anticoagulant therapy than conventional management methods [26, 39]. Based on the better clinical outcomes, self-managed oral anticoagulant therapy could potentially improve the standard of care for patients with mechanical heart valves [18]. 


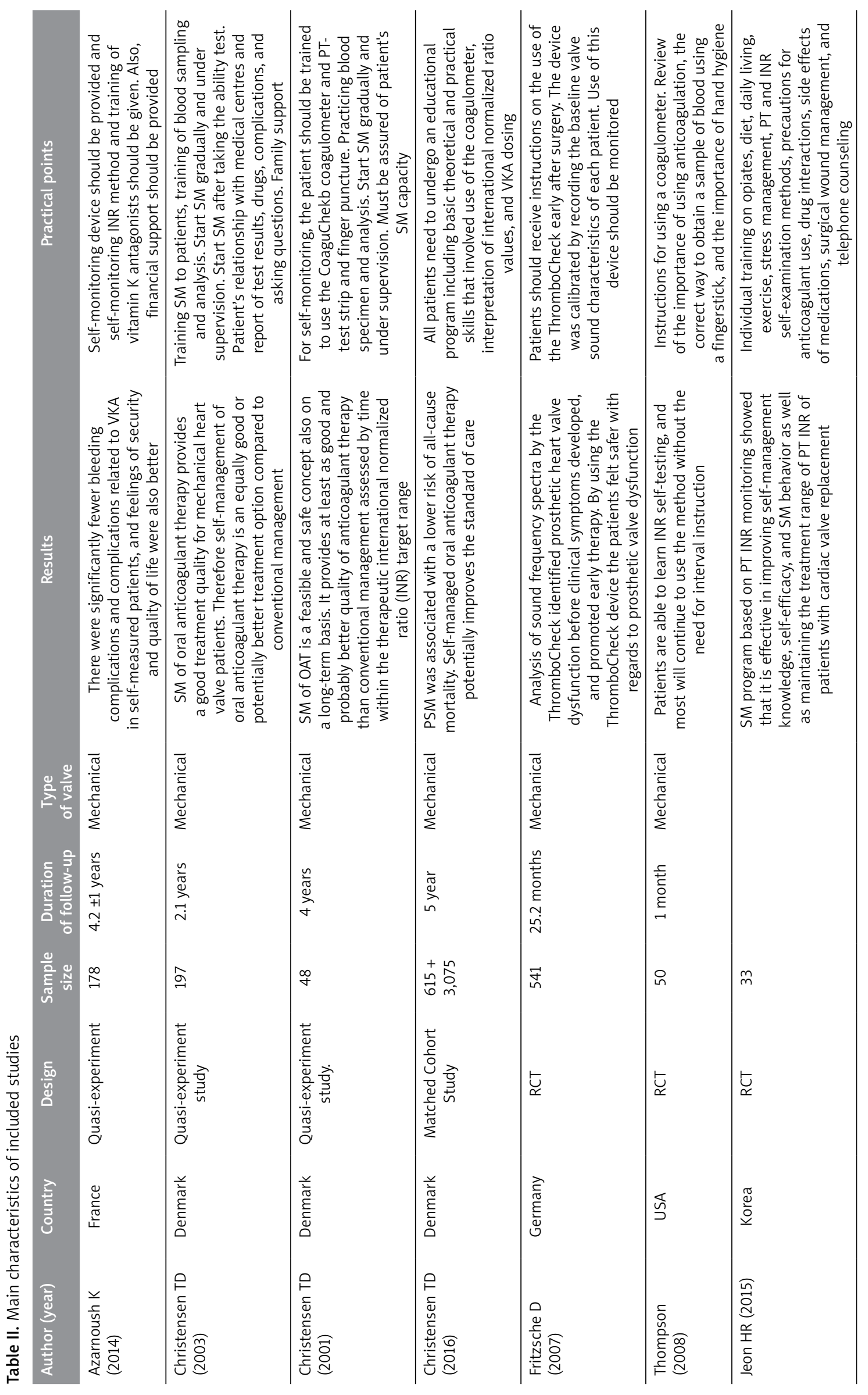




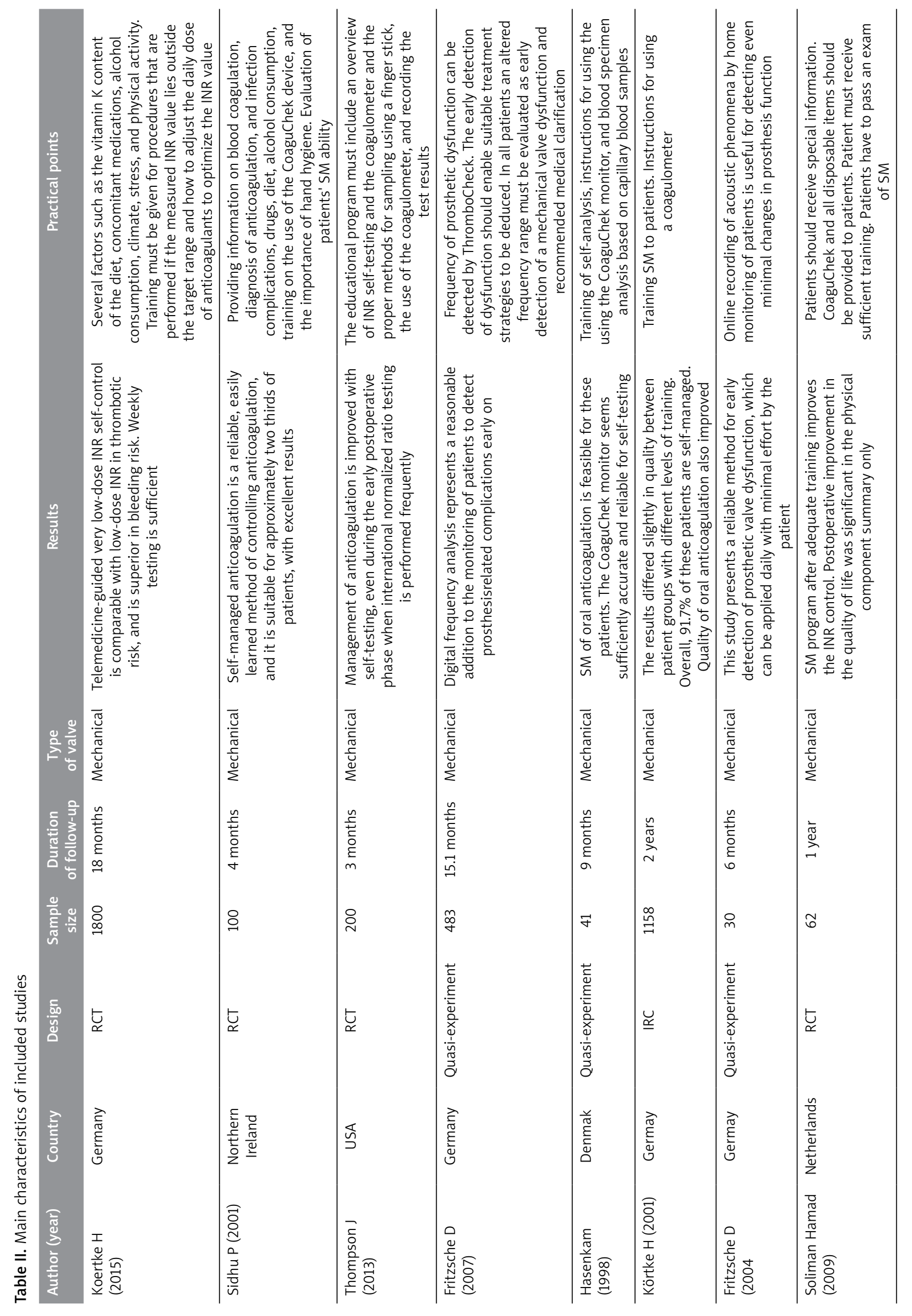




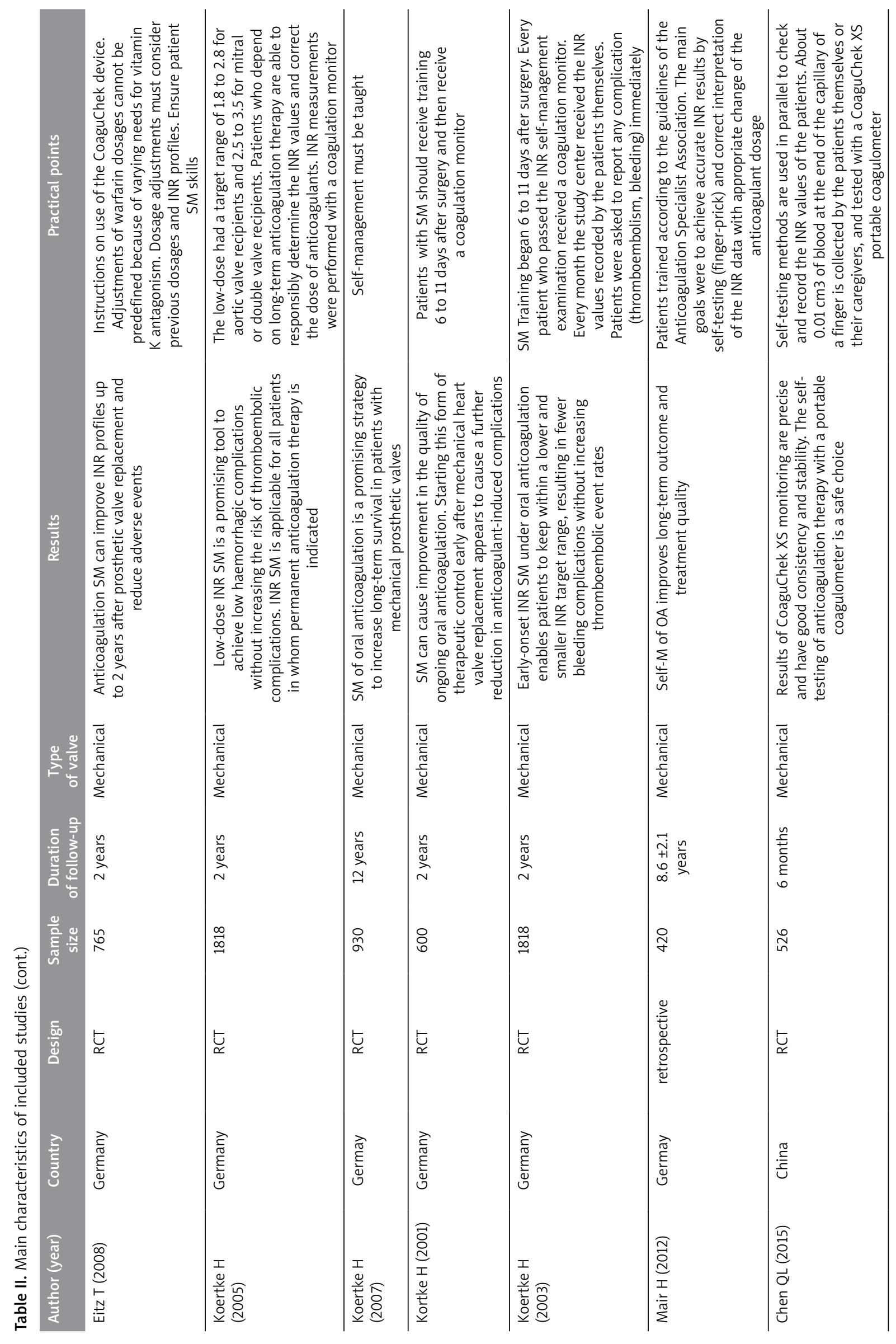




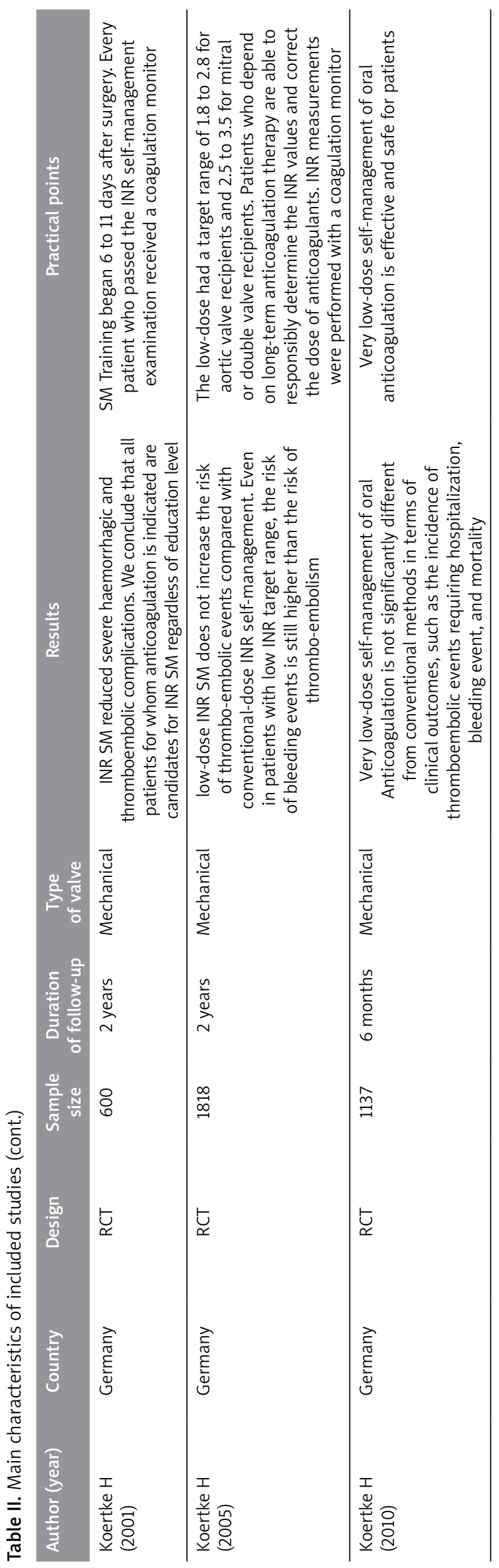

Moreover, through the application of self-management methods and programs, self-efficacy, knowledge, and selfmanagement behaviours will be strengthened in these patients. Thus, they will feel more safe and experience a better quality of life [24, 27, 34]. In fact, oral anticoagulant self-management is a promising strategy to increase long-term survival in patients with mechanical prosthetic valves [30]. In a prospective cohort study, Christensen et al. showed that the incidence rate could be at a lower level in self-management of anticoagulant therapy. They also concluded that the patients' self-management showed a lower risk of all-cause mortality after 5 years compared to the conventional management [18]. According to the published studies, the patients with self-management of anticoagulant therapy were significantly within the target therapeutic range of the INR in comparison with conventional methods [19, 26, 28, 31, 38, 39]. It has also been shown that the complications associated with anticoagulant therapy (including haemorrhagic and thromboembolic incidences) in patients with self-management are significantly less common [28, 30-32, 34, 36]. If the self-management program is applied in the early stages of heart valve replacement, it will be more effective in the alleviation of side effects of anticoagulant therapy [31, 32]. Thus, self-management in patients with sufficient training could improve the INR control [38]. In this regard, the study of Christensen et al. (2016) showed that the rate of thromboembolic events in the self-management and conventional groups were $1.62 \%$ and $1.97 \%$, respectively. In both groups, the bleeding rate was $1.11 \%$ and $1.44 \%$, respectively [18]. In another study, the rate of thromboembolic incidences was $1.2 \%$ in the selfmanagement group and $2.1 \%$ in the conventional group. Also, in this study the rate of bleeding was $1.7 \%$ and $2.6 \%$, respectively [31].

\section{INR self-testing}

INR self-testing is one of the most commonly investigated aspects of self-management in studies. Chen et al. stated that the self-testing in anticoagulation therapy with a portable coagulometer is a safe choice for patients receiving anticoagulation therapy after mechanical heart valve replacement. This method has a promising future because it reduces the cost and time required for re-examination [35]. Thompson et al. showed that management of anticoagulation with warfarin after mechanical valve replacement is improved with self-testing, even during the early postoperative phase when international normalized ratio testing is performed frequently [25]. Thompson et al. reported that the mean results of INR testing obtained from a coagulometer and self-testing correlated well with the values obtained by laboratory determination [20]. Evidence also shows that this method has a positive effect on health and quality of patients' life. Also, by using INR self-testing, anticoagulant management could be improved. However, different studies regarding the prevalence of complications in both traditional and self-testing methods have obtained different results. As was shown in the study of Azarnoush 
et al. (2014), the rate of bleeding was $15.4 \%$ in the selftesting group and $37.5 \%$ in the traditional group. Also, the rate of all events related to VKA in both groups was 15.4 and 42.5, respectively [27]. However, in the study of Thompson et al. from 2013, the prevalence of transient ischaemic attack was $2 \%$ in the self-testing group and $1 \%$ in the traditional method group; the rate of bleeding in the groups was $5 \%$ and $3 \%$, respectively [25].

\section{Low-dose INR self-management}

International normalized ratio self-management can significantly reduce INR fluctuations, bleeding, and thromboembolic events compared to INR control managed by general practitioners. However, even patients with INR self-management may have an increased risk of bleeding if their INR value is above 3.5 [29]. There are various studies in this field which evaluated the compliance, clinical complications, and survival rates of patients after mechanical heart valve replacement with low-dose INR selfmanagement compared with conventional-dose anticoagulation [21, 29, 33, 42]. In two of these studies, low-dose anticoagulation is considered with a target INR range of 1.8-2.8 for aortic valve replacement and 2.5-3.5 for mitral or double valve replacement $[29,33]$. These studies demonstrated that low-dose INR self-management is a promising tool for the achievement of fewer bleeding complications without increasing the risk of thromboembolic complications [29]. Also, low-dose INR self-management does not increase the risk of thrombo-embolic events in comparison with the conventional dose of INR self-management, even in patients with a low INR target range. The risk of bleeding events is still higher than the risk of thromboembolism [33]. In this regard, the study of Koertke et al. (2005) showed that the thromboembolic incidence rate in the low-dose INR self-management group was $0.18 \%$, and in the conventional-dose anticoagulation group it was $0.4 \%$. The bleeding rate in these 2 groups was $0.74 \%$ and $1.2 \%$, respectively [29]. In another study, the rate of thromboembolic events was $0.19 \%$ in the low-dose INR self-management group and $0.37 \%$ in the conventional-dose anticoagulation group. Also, the rate of bleeding in both groups was $1.42 \%$ and $1.52 \%$, respectively [33].

Another study evaluated a telemedicine-guided, very low-dose, international normalized ratio, INR target range of 1.6-2.1 for aortic valve replacement and 2.0-2.5 for mitral valve replacement or double valve replacement, this study has shown that telemedicine-guided, very low-dose INR self-control is comparable with low-dose INR in thrombotic risk, and has a high bleeding risk [21]. However, another study showed that very low-dose self-management of oral anticoagulation is not significantly different from conventional methods in terms of clinical outcomes, such as the incidence of thromboembolic events requiring hospitalization, bleeding events, and mortality [42]. The results of this study demonstrated the efficacy and safety of very low-dose INR self-management.

\section{Heart valve function in self-monitoring}

One of the complications of heart valve replacement in post-surgery, which causes severe problems affecting treatment quality as well as the life quality, is valve dysfunction. Although the diagnosis can be made by imaging studies, clinical symptoms commonly precede the diagnostic procedures. In this regard, 3 studies have been conducted with the aim of determining the ability and advantages of diagnosing valvular dysfunction by the patient and self-monitoring through home monitoring methods [23, 37, 40].

Digital frequency analysis represents a reasonable addition to the monitoring of patients after artificial heart valve replacement to detect prosthesis related complications early on [37]. The Thrombo Check device is used to diagnose dysfunction of the valve frequency spectrum, which shows that this device as part of a monitoring system is frequently associated with recognizable valve dysfunction [23, 37 , 40]. This is a reliable diagnostic method for early detection of prosthetic valve dysfunction, which can be applied daily with minimal effort by the patient [40]. Application of this method detects valve dysfunction prior to the appearance of clinical symptoms, and it improves primary treatment [23]. Before the application of this device, the patients should be trained, and the device should be calibrated by recording the baseline valve sound characteristics [23].

\section{Therapeutic range of INR}

For patients with mechanical heart valves, it is necessary to consider the treatment range based on the position of the valve for proper INR control. As a result of this systematic review, it has been found that in several studies the therapeutic range of INR has been considered 2.5 to 4.5 in both traditional and self-management methods and in each type of valve position [31, 34, 36, 38, 41]. In some studies, the range of INR therapy is considered $2-3$ in each position [26, 39]. In another study, the therapeutic range of INR was considered 2 to 3 for aortic and tricuspid valves and 2.5-3.5 for mitral and multiple valves, respectively [22]. In low-dose INR self-management studies, the therapeutic range has been considered 1.8-2.8 for aortic valves and 2.5-3.5 for mitral and double valves, respectively [29, 32, 33, 42]. In the study of Koertke (2010) in the filed of very low dose self-management method, the therapeutic range in aortic valves was 1.6-2.1, and in mitral and double valves was 2-2.5 [42]. In another study in which the lowintensity anticoagulation therapy method was examined, the therapeutic range of INR was considered 1.5-1.8 in aortic valves, $1.8-2$ in mitral and double valves, and $2-2.5$ in TVR valves [35]

\section{Conclusions}

According to this review study, self-management is a learnable behavior for these patients that if the necessary prerequisites and training are provided, these patients can manage their condition. Self-management in these patients is applicable in the aspects of anticoagulation ther- 
apy self-management, INR self-testing, low-dose INR selfmanagement, and heart valve function self-monitoring, and mostly mechanical valve studies. In this method, with proper control of INR levels and anticoagulation therapy, the incidence of complications will be reduced, and patients can diagnose functional disorders in the early stages through monitoring of the valve function to prevent the progression of complications. Thus, self-management in these patients is safe, with better clinical and psychological results than for the usual management method, which eventually can improve the quality of treatment and quality of life in these patients.

\section{Acknowledgments}

This study was financially supported by the Hamadan University of Medical Sciences of Iran.

\section{Disclosure}

The authors report no conflict of interest.

\section{References}

1. Sun JC, Davidson MJ, Lamy A, Eikelboom JW. Antithrombotic management of patients with prosthetic heart valves: current evidence and future trends. Lancet 2009; 374: 565-576.

2. Supino PG, Borer JS, Preibisz J, Bornstein A. The epidemiology of valvular heart disease: a growing public health problem. Heart Failure Clinics 2006; 2: 379-393.

3. Hansen L, Winkel S, Kuhr J, Bader R, Bleese N, Riess FC. Factors influencing survival and postoperative quality of life after mitral valve reconstruction. Eur J Cardiothorac Surg 2010; 37: 635-644.

4. Butchart EG, Gohlke-Bärwolf C, Antunes MJ, Tornos P, De Caterina R, Cormier B, Prendergast B, lung B, Bjornstad H, Leport C, Hall RJC, Vahanian A, Working Groups on Valvular Heart Disease, Thrombosis, and Cardiac Rehabilitation and Exercise Physiology, European Society of Cardiology. Recommendations for the management of patients after heart valve surgery. Eur Heart J 2005; 26: 2463-2471.

5. Akins CW. Results with mechanical cardiac valvular prostheses. Ann Thorac Surg 1995; 60: 1836-1844.

6. Rahimtoola SH. Choice of prosthetic heart valve in adults: an update. J Am Coll Cardiol 2010; 55: 2413-2426.

7. Yanagawa B, Whitlock RP, Verma S, Gersh BJ. Anticoagulation for prosthetic heart valves: unresolved questions requiring answers. Curr Opin Cardiol 2016; 31: 176-182.

8. Thourani VH, Suri RM, Gunter RL, Sheng S, O'Brien SM, Ailawadi G, Szeto WY, Dewey TM, Guyton RA, Bavaria JE, Babaliaros V, Gammie JS, Svensson L, Williams M, Badhwar V, Mack MJ. Contemporary real-world outcomes of surgical aortic valve replacement in 141,905 low-risk, intermediate-risk, and high-risk patients. Ann Thorac Surg 2015; 99: 55-61.

9. Brennan JM, Edwards FH, Zhao Y, O’Brien S, Booth ME, Dokholyan RS, Douglas PS, Peterson ED, DEcIDE AVR (Developing Evidence to Inform Decisions about Effectiveness-Aortic Valve Replacement) Research Team. Long-term safety and effectiveness of mechanical versus biologic aortic valve prostheses in older patients: results from the Society of Thoracic Surgeons Adult Cardiac Surgery National Database. Circulation 2013; 127: 1647-1655.

10. Lunel C, Laurent M, Corbineau H, Boulmier D, Chaperon J, Guillo P, Dewitte JD, Leguerrier A. Return to work after cardiac valvular surgery. Retrospective study of a series of 105 patients. Archives des Maladies du Coeur et des Vaisseaux 2003; 96: 15-22.

11. Shah SGS, Barnett J, Kuljis J, Hone K, Kaczmarski R. Factors determining patients' intentions to use point-of-care testing medical devices for self-monitoring: the case of international normalized ratio self-testing. Patient Prefer Adherence 2013; 7: 1-14.

12. Gadisseur A, Breukink-Engbers W, Van Der Meer F, Van Den Besselaar A, Sturk A, Rosendaal F. Comparison of the quality of oral anticoagulant therapy through patient self-management and management by specialized antico- agulation clinics in the Netherlands: a randomized clinical trial. Arch Intern Med 2003; 163: 2639-2646.

13. Heneghan C, Ward A, Perera R, Self-Monitoring Trialist Collaboration; Bankhead C, Fuller A, Stevens R, Bradford K, Tyndel S, Alonso-Coello P, Ansell J, BeythR, Bernardo A, Christensen TD, Cromheecke ME, Edson RG, Fitzmaurice D, Gadisseur APA, Garcia-Alamino JM, Gardiner C, Hasenkam JM, Jacobson A, Kaatz S, Kamali F, Khan TI, Knight E, Körtke H, Levi M, Matchar D, Menéndez-Jándula B, Rakovac I, Schaefer C, Siebenhofer A, Souto JC, Sunderji R, Gin K, Shalansky K, Völler H, Wagner O, Zittermann A. Self-monitoring of oral anticoagulation: systematic review and meta-analysis of individual patient data. Lancet 2012; 379: 322-334.

14. Grunau BE, Wiens MO, Harder KK. Patient self-management of warfarin therapy: pragmatic feasibility study in Canadian primary care. Canad Fam Phys 2011; 57: e292-e298.

15. Thompson JL, Sundt TM, Sarano ME, Santrach PJ, Schaff HV. In-patient international normalized ratio self-testing instruction after mechanical heart valve implantation. Ann Thoracic Surg 2008; 85: 2046-2050.

16. Wells PS, Brown A, Jaffey J, McGahan L, Poon M-C, Cimon K. Safety and effectiveness of point-of-care monitoring devices in patients on oral anticoagulant therapy: a meta-analysis. Open Medicine 2007; 1: e131.

17. Moher D, Liberati A, Tetzlaff J, Altman DG. Preferred reporting items for systematic reviews and meta-analyses: the PRISMA statement. Ann Intern Med 2009; 151: 264-269.

18. Christensen TD, Skjoth F, Nielsen PB, Maegaard M, Grove EL, Larsen TB. Selfmanagement of anticoagulant therapy in mechanical heart valve patients: a matched cohort study. Ann Thoracic Surg 2016; 101: 1494-1499.

19. Sidhu P, O'Kane HO. Self-managed anticoagulation: results from a two-year prospective randomized trial with heart valve patients. Ann Thoracic Surg 2001; 72: 1523-1527.

20. Thompson JL, Sundt TM, Sarano ME, Santrach PJ, Schaff HV. In-patient international normalized ratio self-testing instruction after mechanical heart valve implantation. Ann Thoracic Surg 2008; 85: 2046-2050.

21. Koertke H, Zittermann A, Wagner O, Secer S, Huth CO, Sciangula A, Saggau W, Sack FU, Ennker J, Cremer J, Musumeci F, Gummert JF. Telemedicineguided, very low-dose international normalized ratio self-control in patients with mechanical heart valve implants. Eur Heart J 2015; 36: 1297-1305.

22. Christensen TD, Andersen NT, Attermann J, Hjortdal VE, Maegaard M, Hasenkam JM. Mechanical heart valve patients can manage oral anticoagulant therapy themselves. Eur J Cardiothorac Surg 2003; 23: 292-298.

23. Fritzsche D, Schenk S, Eitz T, Mantas J, Horstkotte D, Koerfer R. Patient selfmonitoring of prosthetic heart valve function. J Heart Valve Dis 2007; 16: 558-566.

24. Jeon HR, Park JS. Development and application of a self management program based on prothrombin INR monitoring for patients with cardiac valve replacement. J Korean Acad Nurs 2015; 45: 554-564.

25. Thompson JL, Burkhart HM, Daly RC, Dearani JA, Joyce LD, Suri RM, Schaff HV. Anticoagulation early after mechanical valve replacement: Improved management with patient self-testing. J Thoracic Cardiovasc Surg 2013; 146: 599-604.

26. Christensen TD, Attermann J, Pilegaard HK, Andersen NT, Maegaard M, Hasenkam JM. Self-management of oral anticoagulant therapy for mechanical heart valve patients. Scand Cardiovasc J 2001; 35: 107-113.

27. Azarnoush K, Dorigo E, Pereira B, Dauphin C, Geoffroy E, Dauphin N, D'Ostrevy N, Legault B, Camilleri L. Mid-term results of self-testing of the international normalized ratio in adults with a mechanical heart valve. Thrombosis Res 2014; 133: 149-153.

28. Eitz T, Schenk S, Fritzsche D, Bairaktaris A, Wagner O, Koertke H, Koerfer R. International normalized ratio self-management lowers the risk of thromboembolic events after prosthetic heart valve replacement. Ann Thorac Surg 2008; 85: 949-954.

29. Koertke H, Zittermann A, Minami K, Tenderich G, Wagner O, El-Arousy M, Krian A, Ennker J, Taborski U, Klövekorn WP, Moosdorf R, Saggau W, Morshuis M, Koerfer J, Seifert D, Koerfer R. Low-dose international normalized ratio self-management: a promising tool to achieve low complication rates after mechanical heart valve replacement. Ann Thorac Surg 2005; 79: 1909-1914.

30. Koertke H, Zittermann A, Wagner O, Koerfer R. Self-management of oral anticoagulation therapy improves long-term survival in patients with mechanical heart valve replacement. Ann Thorac Surg 2007; 83: 24-29.

31. Kortke H, Korfer R. International normalized ratio self-management after mechanical heart valve replacement: is an early start advantageous? Ann Thorac Surg 2001; 72: 44-48.

32. Koertke H, Minami K, Boethig D, Breymann T, Seifert D, Wagner O, Atmacha N, Krian A, Ennker J, Taborski U, Klövekorn WP, Moosdorf R, Saggau W, 
Koerfer R. INR self-management permits lower anticoagulation levels after mechanical heart valve replacement. Circulation 2003; 108 Suppl 1: li75-li78.

33. Koertke H, Zittermann A, Tenderich G, Wagner O, El-Arousy M, Krian A, Ennker J, Taborski U, Klovekorn WP, Moosdorf R, Saggau W, Koerfer R. Low-dose oral anticoagulation in patients with mechanical heart valve prostheses: final report from the early self-management anticoagulation trial II. Eur Heart J 2007; 28: 2479-2484.

34. Mair H, Sachweh J, Sodian R, Brenner P, Schmoeckel M, Schmitz C, Reichart B, Daebritz S. Long-term self-management of anticoagulation therapy after mechanical heart valve replacement in outside trial conditions. Interact Cardiovasc Thorac Surg 2012; 14: 253-257.

35. Chen QL, Dong L, Dong YJ, Zhao SL, Fu B, Wang YQ, Jiang H. Security and cost comparison of INR self-testing and conventional hospital INR testing in patients with mechanical heart valve replacement. J Cardiothorac Surg 2015; 10: 4.

36. Koertke H, Minami K, Bairaktaris A, Wagner O, Koerfer R. INR self-management following mechanical heart valve replacement. J Thromb Thrombolysis 2000; 9 Suppl 1: S41-S45.

37. Fritzsche D, Eitz T, Laczkovics A, Liebold A, Knaut M, Matschke K, Sagie A Mehlhorn U, Horstkotte D, Koerfer R. Early detection of mechanical valve dysfunction using a new home monitoring device. Ann Thoracic Surg 2007; 83: 542-548.

38. Soliman Hamad MA, van Eekelen E, van Agt T, van Straten AHM. Self-management program improves anticoagulation control and quality of life: a prospective randomized study. Eur J Cardiothorac Surg 2009; 35: 265-269.

39. Hasenkam JM, Kimose HH, Grønnesby H, Andersen NT, Halborg J, Attermann J, Pilegaard HK. Self management of oral anticoagulant therapy after heart valve replacement. Ugeskrift for Laeger 1998; 160: 6811-6815.

40. Fritzsche D, Eitz T, Grimmig O, Horstkotte D, Körfer R. Home monitoring of patients after prosthetic valve replacement - a new method of early detection of valve dysfunction. Zeitschrift fur Kardiologie 2004; 93: 664-670.

41. Körtke H, Minami K, Breymann T, Seifert D, Baraktaris A, Wagner O, Kleikamp G, el-Banayosy A, Mirow N, Körfer R. INR self-management after mechanical heart valve replacement: ESCAT (Early Self-Controlled Anticoagulation Trial). Z Kardiol 2001; 90 (Suppl. 6): 118-124.

42. Koertke H, Zittermann A, Wagner O, Ennker J, Saggau W, Sack FU, Cremer J, Huth C, Braccio M, Musumeci F, Koerfer R. Efficacy and safety of very low dose self-management of oral anticoagulation in patients with mechanical heart valve replacement. Ann Thorac Surg 2010; 90: 1487-1493. 